\title{
Homenagem ao professor Alvino Lima
}

Em virtude de aposentadoria compulsória foi homenageado pela Congregação em sessão solene, no dia onze de abril do corrente ano, o Professor Alvino Lima. Inaugurando-se na ocasião, na galeria dos ex-diretores da Faculdade o retrato a óleo do ilustre mestre, saudou-o em nome da Congregação o Professor Jorge Americano.

\section{Oração do Professor Jorge Americano}

"Como vos terá parecido extranho êsse dia 9 de agôsto! Seja por manhã nublada, em que na rua os seres são fantasmas, ou por manhã em que a chuva goteja; ou seja de um sol amarelo que corta a custo a névoa seca; ou dessas manhãs em que o vento frio arrepia; ou de sol claro e cigarras estridentes, chega-nos inexoràvelmente o dia em que termina a carreira universitária.

Toma-se consciência dêle pelo ramo de flores acompanhado de uma frase gentil; pelo almôço mais lauto, pela voz amiga a saudar no outro extremo do telefone, pela campainha insistente do estafeta que traz telegramas, pelos abraços e risos; por tôdas formas suaves com que a vida nos adverte de que o tempo corre sorrateiro.

Mas essa astúcia não impede a vista da burocrática e inexorável folhinha de parede, revelando a data em que a lei decreta o fim de uma etapa da vida.

Fizestes, por certo, nesse dia, o retrospecto caleidoscópico em que passam a primeira infância descuidada, na pequena Rosário do Cateto; recordastes a vinda para 
São Paulo, a escola primária, o curso secundário onde os companheiros impiedosos, de fala descançada, caçoaram da vossa fala sergipana; lembrastes aquele São Paulo dos lampeões a gaz, dos bondes a tração animal, dos tílburis, da antiga Sé e da igreja do Rosário, do velho São Paulo onde sobresaía a Faculdade, com o salão nobre de austeros retratos, a comunicação interna com a igreja de São Francisco, o jardinzinho lateral e o ingênuo jardim dos fundos para onde davam as janelas da sala $n .^{\circ} 2$, que serviam aos estudantes para fugir às aulas depois de haverem respondido à chamada; onde entre os 13 e os 15 anos prestastes os exames preparatórios diante de mestres austeros que usavam fraque e chapéu duro; onde medistes as fôrças balançadas entre a confiança extrema que vos dera em 1904 a admissão ao curso superior e o pânico terror dos trotes ameaçadores.

Novos horizontes, novos amigos, novas aspirações.

O tenente Rocha policiando o Largo de São Francisco e parlamentando com os estudantes que disputavam turbulentamente o direito de salvar a Pátria. A colação de grau em 1908, aos 20 anos, concedida pelas mãos de Dino Bueno, na sua pequena e modesta sala de Diretor, com sanefas vermelhas de algodão e seda.

Haveis recordado depois a roda de prosa na farmácia do interior, a banda tocando no Largo da Matriz às noites de domingo, o Cartório onde destes os passos hesitantes do comêço da advocacia de rendimentos escassos, que vos fêz buscar também, no magistério secundário suprimentos às finanças parcas. Tereis lembrado a doce companheira que a morte ceifou, a suave recomposição da vida por essa que vos deu novas fôrças e a recompensa dos filhos. A mudança para a Capital, onde vos despontou a aspiração de virdes a ser professor desta Faculdade. As aulas de Pedro Lessa, Mamede, Porchat, Ulpiano, Brasílio, Rafael Corrêa, Steidel, João Mendes, Amâncio de Carvalho, João Monteiro, Herculano de Freitas, Gabriel de Rezende pai, Villaboim, Pinto Ferraz, Oliveira Coutinho, Veiga 
Filho, Dino Bueno, Almeida Nogueira, Ernesto Moura, deuses de beca, aprovando e reprovando, discernindo entre o mérito e demérito. Rememorastes por certo a empolgante campanha civilista, a Liga Nacionalista, a Revolução de 1930, a Epopéia de 1932, tudo quanto aconteceu tumultuàriamente, enquanto a vossa aspiração se firmava, no ambicioso e aparentemente inatingível desejo de virdes a ser um dos deuses.

"Tese fechada, ou tese aberta"? "Quais os pontos vulneráveis"? "Por onde serei atacado"?

E, com o "Direito da Retenção", tese brilhantemente defendida perante Francisco Morato, Carlos Maximiliano, Mário Guimarães, João Otaviano de Lima Pereira e eu que vos falc, conquistastes o degrau da livre docência, que posteriormente vos levaria à Cátedra.

A êsse tempo já o alvião inclemente havia demolido as velhas taipas de feitio simples das ingênuas eras, para dar lugar ao pretencioso barroco pesado.

Não tardou que a morte levasse mais um, o saudoso professor José Augusto Cesar cuja vaga viestes em seguida disputar, com a clássica tese - Da Culpa ao Risco - que vos consolidou a reputação de jurista emérito e sôbre o qual vos argüiram Francisco Morato, Filadelfo Azevedo, Hahnemann Guimarães, Lino de Moraes Leme e também eu.

Dos que aqui se assentavam a êsse tempo muitos já se foram, enquanto outros sobrenadam na torrente da vida.

Aos poucos, descobríamos que a idade vinha chegando, pois já muitos começavam a gabar a nossa juventude, enquanto nos cediam precedências ao transpor as portas. E quando olhávamos para traz nas filas da Congregação, já nelas víamos incorporados os alunos irrequietos de pouco antes.

Neste quarto de século, do período mais tumultuário da História, (a era da genas e rangeres de dentes dos 
enfurecidos salvadores Messiânicos), também no Brasil sofremos vicissitudes: a pretexto de ordem, subverteu-se o regime; a pretexto de nacionalismo, implantou-se o ódio; a pretexto de honestidade, impôs-se o arbítrio.

São conhecidos os reflexos de tais deformações sôbre a mocidade. Mas, por bem da Escola, feito professor, não esposastes doutrinas "salvadoras".

O cotidiano exemplo de uma vida reta, a calma exposição da doutrina, o trato ameno para com colegas, alunos e funcionários, foram fatôres preponderantes da vossa eleição à Diretoria, ao termo de cujo mandato findastes também a carreira do magistério. Transpusestes duras crises na direção administrativa, disciplinar e educacional, guardando o bom senso, a serenidade e o equilibrio.

Podeis estar seguro, neste balanço de contas, ao termo da etapa que passou, que foi grande o saldo favorável. $\mathrm{Na}$ cerimônia simples, da inauguração do vosso retrato na galeria dos Diretores, a Congregação dos Professôres quer salientar, por meu intermédio, que não pratica mera formalidade, mas dela se serve para vos dar grata e cordialmente a demonstração da alta estima que por vós tem e continuará a ter, durante a fase augusta e respeitável ora iniciada e que esperamos seja longa, reiteradamente produtiva e feliz, tendo em torno os que vos são caros, entre os quais pleiteamos ser contados, de coração.

\section{Discurso do Professor Alvino Lima}

Agradecendo a saudação do Professor Jorge Americano, o Professor Alvino Lima pronunciou o seguinte discurso.

"Se foi possível, pelo estudo e pelo trabalho, conseguir, um dia, realizar o meu ideal de ser professor desta casa, nunca tive a veleidade de pensar em dirigir-lhe os destinos. Entretanto isto aconteceu, exclusivamente em virtude da bondade dos meus dignos colegas de Ciongre- 
gação. Quando pela primeira vez me sentei àquela mesa e contemplei esta galeria dos notáveis diretores, que dirigiram os destinos desta Faculdade, senti-me, sinceramente, pequenino e incapaz de continuar a obra realizada pelos meus antecessores. Conheci-os, desde o notável jurista João Monteiro, meu diretor, quando me matriculei em 1904 nesta Academia. Todos, ilustres professôres, juristas eméritos, políticos de escol, magistrados impolutos, dirigiram com sabedoria, carinho e amor os destinos desta Faculdade. Quê poderia eu fazer para não deslustrar os que me precederam naquela pôsto, que eu então assumia? Quê deveria eu realizar para não ferir, ao de leve que fôsse, as tradições desta casa, o seu renome glorioso e inconfundível? Como deveria eu agir para não decair da confiança que me conferiram os meus dignos colegas? Quê deveria eu fazer para que um dia, quando da colocação do meu retrato ao lado de tão eminentes mestres e diretores, como imperativo da tradição desta casa, eu não me sentisse vexado, ou mesmo apontado como relapso no cumprimento dos meus deveres, tal a responsabilidade que me pesava aos ombros? Neste momento de reflexão, não me atemorisavam os trabalhos a vencer, as fadigas a suportar e nem as responsabilidades que me esperavam. Temi a vossa crítica justa e necessária, e, sobretudo, temi não ter fôrças para servir esta Faculdade tanto quanto a quero, tanto quanto the devo. Em uma palavra: - - temi deslustrá-la e desservi-la. Nesta situação quase angustiosa, não me foi difícil, entretanto, traçar uma norma geral, de conduta: - Seguir as pégadas deixadas pelos meus antecessores, palmilhar o mesmo caminho por êles vencido, seguir-lhes os exemplos e os ensinamentos, e, sobretudo, trabalhar por esta Faculdade, como êles o fizeram - com carinho, dedicação e sacrifício, embora sem as mesmas luzes e sabedoria, mas com o mesmo coração referto de amor a êste templo.

E assim o fiz. Bem? Mal? Julguem os meus ilustres colegas. Certos, porém, devem estar de que tudo fiz para 
servi-la bem, para engrandecê-la, para vê-la maior. Se não consegui, tenho, pelo menos, a consciência de que conservei o que recebi, para entregar a mãos mais hábeis um patrimônio imperecivel e glorioso.

Agradeço-vos, meus colegas, de todo o coração, as palavras que me dirigistes, através da oração proferida pelo meu nobre colega Prof. Jorge Americano; agradeço aos ilustres membros do Conselho Técnico Administrativo a colaboração preciosìssima que sempre me prestaram na solução dos problemas atinentes à administração, e, finalmente, agradeço a colaboração constante e eficaz dos funcionários, com os quais sempre contei, mormente nos momentos mais difíceis e trabalhosos.

Ao meu ilustre amigo e colega, Prof. Gama e Silva, de quem a Faculdade tanto espera, pela sua cultura, sua expressiva e dinâmica capacidade de trabalho e sua atuação enérgica, mas humana e compreensiva, meus sinceros votos de triunfo, no momento em que assume, merecidamente, a direção da nossa querida e iamais olvidada Academia de Direito. 